\title{
Tahar Ben Jelloun, La preghiera dell'assente
}

\section{Simona Rossi}

\section{(2) OpenEdition}

\section{Journals}

\section{Edizione digitale}

URL: https://journals.openedition.org/studifrancesi/38476

DOI: 10.4000/studifrancesi.38476

ISSN: 2421-5856

\section{Editore}

Rosenberg \& Sellier

\section{Edizione cartacea}

Data di pubblicazione: 15 décembre 2004

Paginazione: 663-664

ISSN: 0039-2944

\section{Notizia bibliografica digitale}

Simona Rossi, «Tahar Ben Jelloun, La preghiera dell'assente», Studi Francesi [Online], 144 (XLVIII | III) | 2004, online dal 30 novembre 2015, consultato il 08 mai 2021. URL: http://journals.openedition.org/ studifrancesi/38476 ; DOI: https://doi.org/10.4000/studifrancesi.38476

\section{Questo documento è stato generato automaticamente il 8 mai 2021.}

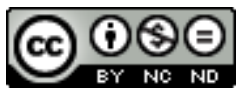

Studi Francesi è distribuita con Licenza Creative Commons Attribuzione - Non commerciale - Non opere derivate 4.0 Internazionale. 


\title{
Tahar Ben Jelloun, La preghiera dell'assente
}

\author{
Simona Rossi
}

\section{NOTIZIA}

Tahar Ben Jelloun, La preghiera dell'assente, Roma, Edizioni Lavoro, 2003 (3a edizione), pp. 200.

1 Il protagonista della Preghiera dell'assente è uno spirito. Un assente del mondo dei vivi, un uomo non più uomo che dopo una vita angusta e priva di passioni da professore di filosofia in un liceo periferico, grazie alla morte si sente finalmente libero. La morte gli regala infatti una libertà totale, che non conosceva: la libertà di pensare, di cercarsi, d'immaginare. E questo essere in evoluzione, in piena fase di completamento, troverà forma incarnandosi in un bambino muto nato nel cimitero marocchino Bab Ftuh di Fez. Di lui si occuperanno tre strani individui, chiamati dalla voce della sua defunta nonna, Lalla Malika: Sindbad, sapiente accusato di follia divenuto vagabondo; Boby, un mendicante convinto di poter essere un cane; infine Yamna, lo spirito di una vecchia prostituta che torna a vivere nel ruolo di amorosa nutrice, con il compito di educare alla parola il misterioso fanciullo. I tre, al servizio del Supremo Segreto, intraprenderanno la traversata del Marocco da nord a sud, diretti verso la tomba dello sheikh Ma'al-Aynayn, eroe della resistenza marocchina, mitica figura della lotta per l'indipendenza. Questa la trama del romanzo, scarna e impotente, muta come il bambino. Perché l'autore, Tahar Ben Jelloun, trasporta i suoi lettori in un mondo misterioso, quasi impossibile da afferrare e descrivere, fatto di funamboli e incantatori di serpenti, di "lacrime trattenute sul ciglio" e di "lune così piene e rotonde che rischiano di cadere" (p. 108). Un mondo che si sente sulla pelle, straziante e doloroso ma anche poetico, intriso di una spiritualità talmente antica e lontana che le pagine sembrano rugose, invecchiate. Eppure Tahar Ben Jelloun è uno scrittore moderno, che sa dare voce alla marginalità, ai derelitti dei nostri tempi, e La preghiera dell'assente non è affatto una storia vecchia, bensì il riflesso della realtà odierna del Marocco, un paese 
dalla memoria mutilata, il cui popolo appare triste, umiliato, rassegnato. E, a dimostrazione di questo, i personaggi del romanzo sono solo ombre fuggitive, spesso confusi, smarriti, privi di un nome. Non si può nemmeno parlare solo di una storia, al singolare, perché l'esistere (ammesso che di vera esistenza si possa parlare) dei quattro personaggi principali si afferma attraverso mille altre vicende, attraverso altre esistenze spezzate. Di città in città, così, di villaggio in villaggio, le storie si sdoppiano, s'incrociano, si moltiplicano, si sovrappongono, dipingendo una traversata del paese che in realtà non è altro che una profonda meditazione sull'epoca e su tutto ciò che è andato perduto. Ma che può essere ritrovato.

2 Ecco allora che il trasporto di questo bambino al sud diventa una sfida, un modo per rigenerare la memoria e la vita, per rinnovarle, come del resto il viaggio altro non è che la metafora di un problematico cammino all'interno della memoria di un popolo che ha perso tutto: origini, dignità, voglia di lottare. Il fanciullo al centro della vicenda è dunque l'incarnazione del Marocco stesso, che non trova più la via, non trova voce per raccontarsi. Tahar Ben Jelloun racconta, invece, e lo fa in maniera disarmante, con uno stile vestito di dolorose corazze che pure non mente, non si nasconde dietro ai veli dell'orgoglio o di verità frammentarie e provvisorie. Egli non ci regala nessuna soluzione, però, né per il paese né per i personaggi, il cui viaggio appare senza fine: Yamna torna al mondo della polvere, infatti, pronta ad incarnarsi di nuovo in qualcun altro o qualcos'altro, mentre Boby si perde in una follia priva di confini, dove le immagini di passato, presente e futuro si confondono in un'instancabile danza. Quanto a Sindbad, egli prosegue l'itinerario prefissato con il bambino, fino al momento in cui cominciano a mancargli le forze. Lo consegna allora a tre strane figure evanescenti che giungono a cavallo, poi si spegne nella luce accecante dell'alba. Tutto ricomincia. Il romanzo si chiude con una preghiera particolare del venerdì, la preghiera dell'assente, che equivale alla nostra preghiera dei morti. Essa è dedicata ai corpi anonimi, scomparsi, mai ritrovati, "sepolti in una terra lontana, risucchiati nella solitudine delle sabbie o nei flutti di un mare in tempesta" (p. 200). La forza della Preghiera dell'assente, storia imperfetta e ardita, si annida proprio nella non-conclusione, nella sospensione: "Non cesserò di dire la storia del deserto", afferma infatti l'assente prima di diventare bambino, all'inizio della vicenda. "E voi non vi stancherete di ascoltarla, perché è un enigma. È la storia di dune e di ombre che avanzano lentamente alla ricerca di una riva" (p. 112). È praticamente impossibile non lasciarsi catturare dalla forza d'interrogazione, dalla poesia di un libro che racchiude in sé smarrimento e tenacia, verità e incantesimo. 